\title{
In vitro ammonia release of urea-treated high moisture barley and maize grain
}

\author{
A. Nikulina, C. Sarnataro, C. Fabro, F. Mason and M. Spanghero ${ }^{1}$ \\ University of Udine, Department of Agricultural, Food, Environmental and Animal Sciences, 33100 Udine, Italy
}

KEY WORDS: urea, grain, in vitro fermentation, rumen, ammonia

Received: 5 September 2017

Revised: 29 February 2018

Accepted: $\quad 1$ June 2018

${ }^{1}$ Corresponding author:

e-mail: mauro.spanghero@uniud.it

\begin{abstract}
Rumen nitrogen $(\mathrm{N})$ release from ammoniated wet barley and maize kernels by urea treatment (UT) at harvesting was studied. Untreated samples (CTR) were compared to UT and to samples combined with urea just before the experiment (UA). In Experiment 1, ground CTR, UT and UA samples were fermented in a ruminal in vitro system, and ammonia of fermentation fluid was analysed at 0, 2, 4, 6 and $8 \mathrm{~h}$. The effect of incubation time was observed as ammonia peaked at $4 \mathrm{~h}$ of fermentation (10.24 vs 9.01 and $7.20 \mathrm{mg} \cdot \mathrm{dl}^{-1}$, respectively at 0 and $8 \mathrm{~h}, P<0.01$ ). Also, the effect of treatment was stated when UT released less ammonia than UA treatment (9.76 vs $10.52 \mathrm{mg} \cdot \mathrm{dl}^{-1}, P<0.05$ ), while the CTR samples showed the least ammonia N concentrations $(P<0.01)$. In Experiment 2, the water N solubility of CTR and UT of both cereal samples prepared in three physical forms (whole grain, coarsely ground and milled) was examined. Samples were incubated in flasks with distilled water for 1, 2, 4, 6 and $8 \mathrm{~h}$ and $\mathrm{N}$ was measured in filtered residues to calculate $\mathrm{N}$ solubility. The UT samples, regardless cereal type, solubilised more $\mathrm{N}$ in the milled than in the whole form with the coarse form in the middle (43.7 vs $15.3 \%, 32.4$ vs $14.0 \%$ and 20.3 vs $9.2 \%$ for milled, coarse and whole form, respectively; treatment $x$ physical form interaction: $P<0.01$ ). The $\mathrm{N}$ added to wet cereal kernels by the urea treatment was released in the rumen fermentation liquid more slowly than that simply added as urea before incubation. Based on solubility data, the treated whole or cracked kernels exhibited a slower $\mathrm{N}$ release than milled ones.
\end{abstract}

\section{Introduction}

The treatment of high moisture cereal grains with urea and ureases at harvesting is a method of conservation based on an ammonisation process ammonia produced by urea hydrolysis penetrates the kernels, binds with the vegetal matrix and preserves wet grains (Ørskov and Greenhalgh, 1977; Ørskov et al., 1979).

Researchers have repeatedly evaluated the nutrient utilisation of such treated cereals. Humer and Zebeli (2017) recently reviewed feeding and metabolism trials concerning ammoniated cereals fed to ruminants and found variable results in terms of animal performance with a scarce amount of information available about the modifications in the rumen utilisation due to the treatment.

The experimental hypothesis of the present paper is that the rumen release of ammonia from the treated grain matrix could be slower than a rapid diffusion and can be dependent on the physical form of cereals fed to animals. This supposition, if confirmed, would allow to consider the urea treatment as not a simple way to preserve wet cereals but also as a method to add slowly releasable $\mathrm{N}$ into the rumen, with potential beneficial effects on ru- 
men microbial growth and $\mathrm{N}$ utilisation. Therefore, this research concerns the in vitro evaluation of the dynamic of ammonia release from high moisture whole barley (Hordeum vulgare L.) and maize (Zea mays subsp. mays) grains mixed with urea and a commercial product containing ureases. The study was based on an in vitro test of rumen fermentation, where the release of $\mathrm{N}$ was measured as concentration of ammonia in the fermentation fluid and resulted from the solubilisation process, as well as from the degradation and uptake by microbes. A further experiment examined the $\mathrm{N}$ release from urea treated cereals in three physical forms (whole, cracked or milled). The latter experiment was a water $\mathrm{N}$ solubility test, and not an ammonia measure from an in vitro fermentation, to avoid the expected relevant impact of substrate particle size on in vitro microbial growth and, consequently, on ammonia uptake.

\section{Material and methods}

\section{Treatments}

In total, $40 \mathrm{~kg}$ of conventional air-dried barley and maize grains were collected over 4 weeks $(10 \mathrm{~kg}$ per week) from the same feedstock and bulk per cereal type. Samples of each cereal were collected to be used as a controls (CTR) and were used to prepare the urea-treated (UT) grains by mixing in laboratory the whole untreated grains with urea and a commercial complementary compound feed (14 and $5 \mathrm{~g} \cdot \mathrm{kg}^{-1}$ of grain, respectively), developed to enable the conversion of urea to ammonia in grain and other feeding stuffs (Maxammon ${ }^{\mathrm{TM}}$; Harbro Ltd, Turriff, $\mathrm{UK})$. Water was also added to the mixture $\left(56 \mathrm{~g} \cdot \mathrm{kg}^{-1}\right.$ grain) to simulate harvesting of wet kernels.

The UT cereals were kept for 21 days in anaerobic conditions at the room temperature $\left(22^{\circ} \mathrm{C}\right)$ to allow urea to be transformed into ammonia and penetrate the whole kernels inside. Further, all treated grains were sampled for chemical analysis, sealed and stored in airtight bags during the experimental period at $4{ }^{\circ} \mathrm{C}$. Finally, urea-added (UA) treatment was also tested, where feed-grade urea was added to the untreated grains or meals just before the incubations and in the amounts corresponding to the UT treatment.

\section{In vitro experiments}

A rumen fermentation (Experiment 1) and a solubility experiment (Experiment 2) were performed using samples obtained by the same original batch.
In Experiment 1, for each cereal (barley and maize), CTR, UT and UA samples were milled to $1 \mathrm{~mm}$ (Pulverisette; Fritsch, Idar-Oberstein, Germany) and used in three subsequent fermentation runs, following the method of Cooke et al. (2009).

During each fermentation, samples were incubated in duplicate in 12 Erlenmeyer flasks $(250 \mathrm{ml})$ containing $200 \mathrm{ml}$ of rumen liquid and a nutrient solution mixture (1:4 ratio, $\mathrm{v} / \mathrm{v})$ and maintained at $39{ }^{\circ} \mathrm{C}$ in a water bath for $24 \mathrm{~h}$. Nutrient solution contained bicarbonate-mineral-distilled water mixture (1:1:2, as described by Cooke et al. (2009)). Rumen fluid for each fermentation run was obtained at a slaughterhouse from cull dairy cows ( $\sim 4$ cows per rumen inoculum) and was delivered immediately to the laboratory in airtight glass bottles refluxed with $\mathrm{CO}_{2}$ and immersed in thermoses filled with $39{ }^{\circ} \mathrm{C}$ water. In the laboratory, rumen fluid was strained through $1-\mathrm{mm}$ wire mesh filter and added to the nutrient solution under constant infusion of $\mathrm{CO}_{2}$.

The amount of the incubated substrate was based on the same $\mathrm{N}$ content $(51 \pm 2 \mathrm{mg})$, resulting in $2.52 \pm 0.41 \mathrm{~g}$ and $3.06 \pm 0.62 \mathrm{~g}$ of dry matter (DM) for barley and maize treatments, respectively. At each sampling time $(0,2,4,6$ and $8 \mathrm{~h})$ the $\mathrm{pH}$ of the fermentation fluid was measured and $10 \mathrm{ml}$ samples of fermentation fluid from each flask were collected for ammonia nitrogen $\left(\mathrm{NH}_{3}-\mathrm{N}\right.$ ) determination (samples acidified with $0.4 \mathrm{ml}$ of $9 \mathrm{~N} \mathrm{H}_{2} \mathrm{SO}_{4}$ ).

The Experiment 2 was conducted according to Căpriţă et al. (2010) with some modifications. For each cereal (barley and maize), CTR and UT samples were prepared in three physical forms: whole grain (whole), coarsely milled (coarse) with a coffee mill to approximately $1 / 6$ of the whole kernel, and milled to $1 \mathrm{~mm}$ (milled), providing 12 treatments in total. Samples were weighed $(500 \mathrm{mg}$ of DM) into duplicate Erlenmeyer flasks $(100 \mathrm{ml})$ and incubated with $25 \mathrm{ml}$ of distilled water in a shaking $(120 \mathrm{rpm})$ water bath $\left(25^{\circ} \mathrm{C}\right)$ for five incubation periods $(1,2,4,6$ and $8 \mathrm{~h})$. At the end of each incubation period, the contents of the flask were filtered through ash-free filters (Whatman no. 541, $20 \mu \mathrm{m}$ of porosity), dried at $60^{\circ} \mathrm{C}$ overnight and then analysed for $\mathrm{N}$ content. The whole trial was repeated once.

\section{Chemical analysis}

Kernels of CTR and UT cereals were pre-dried at $60{ }^{\circ} \mathrm{C}$ overnight in a forced-air oven and then milled to $1 \mathrm{~mm}$ (Pulverisette; Fritsch, Idar-Oberstein, 
Germany). The $\mathrm{pH}$ measurements were performed using a glass electrode connected to a $\mathrm{pH}$ meter (GPL 22, Crison Instruments, S.P.A., Barcelona, Spain) according to Martillotti and Puppo (1985): $10 \mathrm{~g}$ of meals and kernels of CTR and UT cereals were mixed with $100 \mathrm{ml}$ of distilled water. The meals of CTR and UT cereals were analysed for the crude protein (CP), DM and ash contents by the Kjeldahl method, by drying at $105^{\circ} \mathrm{C}$ for $3 \mathrm{~h}$ and by ashing at $550{ }^{\circ} \mathrm{C}$ for $2 \mathrm{~h}$ on incinerated samples, respectively (methods 976.05; 930.15 and 942.05 according to AOAC International (2000), respectively).

Samples of fermentation fluid were centrifuged for $\mathrm{NH}_{3}-\mathrm{N}$ determination and analysed spectrophotometrically using a modified Berthelot reaction method (Krom, 1980) with the continuous flow SAN++ analyser (Skalar Analytical B.V., Breda, Netherlands).

\section{Statistical analysis}

The analytical determinations of feeds were statistically analysed as factorial design according to the following model:

$$
\mathrm{Y}_{i j k}=\mu+\alpha_{i}+\beta_{j}+(\alpha \beta)_{i j}+\varepsilon_{i j k}
$$

The data from experiments were statistically analysed as factorial design with repeated measures (Experiment 1) and as factorial design (Experiment 2), according to the following models:

Experiment 1:

$$
\begin{gathered}
\mathrm{Y}_{i j k m n}=\mu+\alpha_{i}+\beta_{j}+\gamma_{k}+\zeta_{m}+\eta_{(i j k m) n}+(\alpha \beta)_{i j}+(\alpha \zeta)_{i m}+ \\
+(\beta \zeta)_{j m}+(\alpha \beta \zeta)_{i j m}+\varepsilon_{i j k m n},
\end{gathered}
$$

Experiment 2:

$$
\begin{aligned}
& \mathrm{Y}_{i j k l m}=\mu+\alpha_{i}+\beta_{j}+\gamma_{k}+\delta_{l}+\zeta_{m}+(\alpha \beta)_{i j}+(\alpha \delta)_{i l}+ \\
& +(\alpha \zeta)_{i m}+(\beta \delta)_{j l}+(\beta \zeta)_{j m}+(\delta \zeta)_{l m}+(\alpha \beta \delta)_{i j l}+ \\
& +(\alpha \beta \zeta)_{i j m}+(\alpha \delta \zeta)_{i l m}+(\delta \beta \zeta)_{l i m}+(\alpha \beta \delta \zeta)_{i j l m}+\varepsilon_{i j k l m},
\end{aligned}
$$

where: $\mathrm{y}$ - measure of experimental unit (single analytical determination or individual flask, Experiment 1; or average of two flasks, Experiment 2); $\mu$ - overall mean; $\alpha_{i}-$ fixed effect of substrate type (CTR, UT, UA, $\mathrm{i}=1,3$, in Experiment 1; CTR, UT, $i=1,2$, in Experiment 2); $\beta_{j}$ - fixed effect of cereal type (barley, maize, $\mathrm{j}=1,2) ; \gamma_{k}$-random effect of incubation run (block, $k=1,3$ or 1,2 in Experiments 1 and 2, respectively); $\eta_{(i \mathrm{k} k m) n}$ - random effect of flasks $(n=1,2)$ in each $i j k m$ combination; $\delta_{l}$ - fixed effect of physical form (whole, coarse, milled, $1=1,3) ; \zeta_{m}-$ fixed effect of sampling time $(0,2,4,6$, and $8 \mathrm{~h}$ and $1,2,4,6$, and $8 \mathrm{~h}$ of fermentation in Experiments 1 and 2, respectively, $\mathrm{m}=1,5)$; and $\varepsilon$ - residual error.

For all statistical analyses, significance was declared at $P \leq 0.05$ and at $P \leq 0.01$.

\section{Results}

\section{Treatments}

Chemical composition and $\mathrm{pH}$ of barley and maize kernel samples are shown in Table 1. The interaction between cereal and treatment was found to be significant $(P<0.05)$ for the DM content, with a higher difference between CTR and UT in maize than in barley. Ash (21.5 vs $12.0 \mathrm{~g} \cdot \mathrm{kg}^{-1} \mathrm{DM}$ for barley and maize, respectively) and CP contents (117.5 vs $90 \mathrm{~g} \cdot \mathrm{kg}^{-1} \mathrm{DM}$ for barely and maize, respectively) were affected by the type of the cereal $(P<0.01)$; furthermore, the treatment with urea increased the $\mathrm{CP}$ content of about 3 percentage points in both kinds of cereal $(P<0.01)$. The urea treatment increased the cereal $\mathrm{pH}$ of 2.6 and 2.1 in whole kernels and in meal of barley and of 1.7 and 2.5 in

\begin{tabular}{|c|c|c|c|c|c|c|c|}
\hline \multirow{3}{*}{ Indices } & \multicolumn{3}{|l|}{ Cereals } & \multicolumn{3}{|c|}{$P$-value ${ }^{1}$} & \multirow{3}{*}{ RMSE } \\
\hline & \multirow{2}{*}{$\begin{array}{l}\text { barley } \\
\text { CTR UT }\end{array}$} & \multicolumn{2}{|l|}{ maize } & \multirow[t]{2}{*}{ C } & \multirow[t]{2}{*}{$T$} & \multirow[t]{2}{*}{$C \times T$} & \\
\hline & & CTR & UT & & & & \\
\hline $\mathrm{DM}, \mathrm{g} \cdot \mathrm{kg}^{-1}$ & $877 \quad 825$ & 870 & 798 & $<0.01$ & $<0.01$ & $<0.05$ & 4.5 \\
\hline Ash, $\mathrm{g} \cdot \mathrm{kg}^{-1} \mathrm{DM}$ & $22 \quad 21$ & 12 & 12 & $<0.01$ & 0.98 & 0.93 & 2.4 \\
\hline $\mathrm{CP}, \mathrm{g} \cdot \mathrm{kg}^{-1} \mathrm{DM}$ & 101134 & 74 & 106 & $<0.01$ & $<0.01$ & 0.42 & 0.9 \\
\hline${ }_{\text {meal }}$ & 5.758 .32 & 6.47 & 8.16 & $<0.01$ & $<0.01$ & $<0.01$ & 0.020 \\
\hline whole kernel & 6.558 .62 & 6.25 & 8.72 & $<0.01$ & $<0.01$ & $<0.01$ & 0.076 \\
\hline
\end{tabular}
whole kernels and in meal of maize $(P<0.01$ for the interaction feed treatment $\times$ cereal type).

Table 1. Chemical composition and pH of control (CTR) and ureatreated (UT) barley and maize kernels before they were used in rumen fermentation experiment and $\mathrm{N}$ solubility test

${ }^{1} \mathrm{C}$ - effect of cereal type, $\mathrm{T}$ - effect of the urea treatment, $C \times T$ - interaction between cereal type and urea treatment; RMSE - root mean square error; DM - dry matter; CP - crude protein

\section{Batch culture incubation with rumen liquid (Experiment 1) and solubility trial (Experiment 2)}

The ammonia $\mathrm{N}$ concentrations and the $\mathrm{pH}$ of the fermentation fluid at different incubation times for feed treatments and cereals are shown in Figure 1. For the ammonia (Figure 1A) there was a significant effect of incubation time and feed treatment $(P<0.01$ for each) and no significant interaction was stated. During incubation ammonia showed a curvilinear pattern with a peak value at $4 \mathrm{~h}$ which was higher than the values at 0 and $8 \mathrm{~h}$ of fermentation $\left(10.24 \mathrm{vs} 9.01\right.$ and $7.20 \mathrm{mg} \cdot \mathrm{dl}^{-1}$, respectively, $P<0.01)$. The CTR samples produced the lowest ammonia N concentrations $(P<0.01)$, while the UT treatment determined (on average 
among incubation times) a lower yield of ammonia than the UA treatment $\left(9.76 \mathrm{vs} 10.52 \mathrm{mg} \cdot \mathrm{dl}^{-1}\right.$, $P<0.05)$. There was no effect of cereal type or interaction between cereal type and incubation time (Figure 1B).
For the $\mathrm{pH}$ of fermentation there was a significant interaction of the incubation time with the feed treatment $(P<0.01)$ and type of cereal $(P<0.01)$. As it can be seen from Figure 1, the interactions are mainly due to a non-perfectly linear decline be-
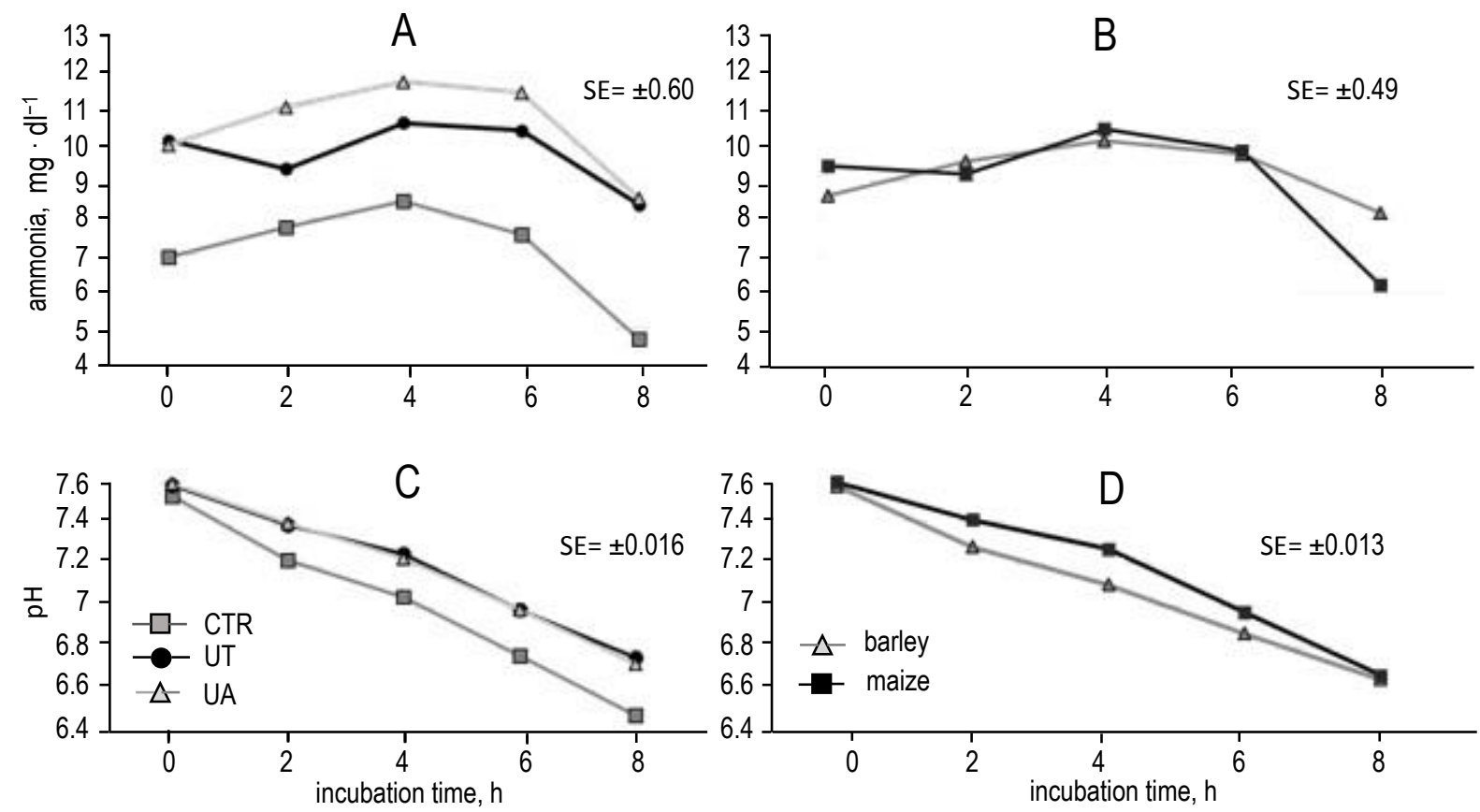

Figure 1. Ammonia $\mathrm{N}$ concentration $(\mathrm{A}$ and $\mathrm{B})$ and $\mathrm{pH}(\mathrm{C}$ and $\mathrm{D})$ of fermentation fluid at different incubation times for feed treatments (CTR - control, UA - urea added and UT - urea treated) and for the two cereals (barley and maize) in in vitro rumen fermentation experiment

Graphs A and B: root mean square error and degrees of freedom: 0.90 and 148, respectively; 'feed treatment' and 'incubation time', $P<0.01$. Graphs $C$ and D: root mean square error and degrees of freedom: 0.024 and 148, respectively; interactions 'feed treatment $\times$ incubation time' and 'feed treatment $\times$ cereal type', $P<0.01$. In each graph the SE (standard error) of the means is reported.

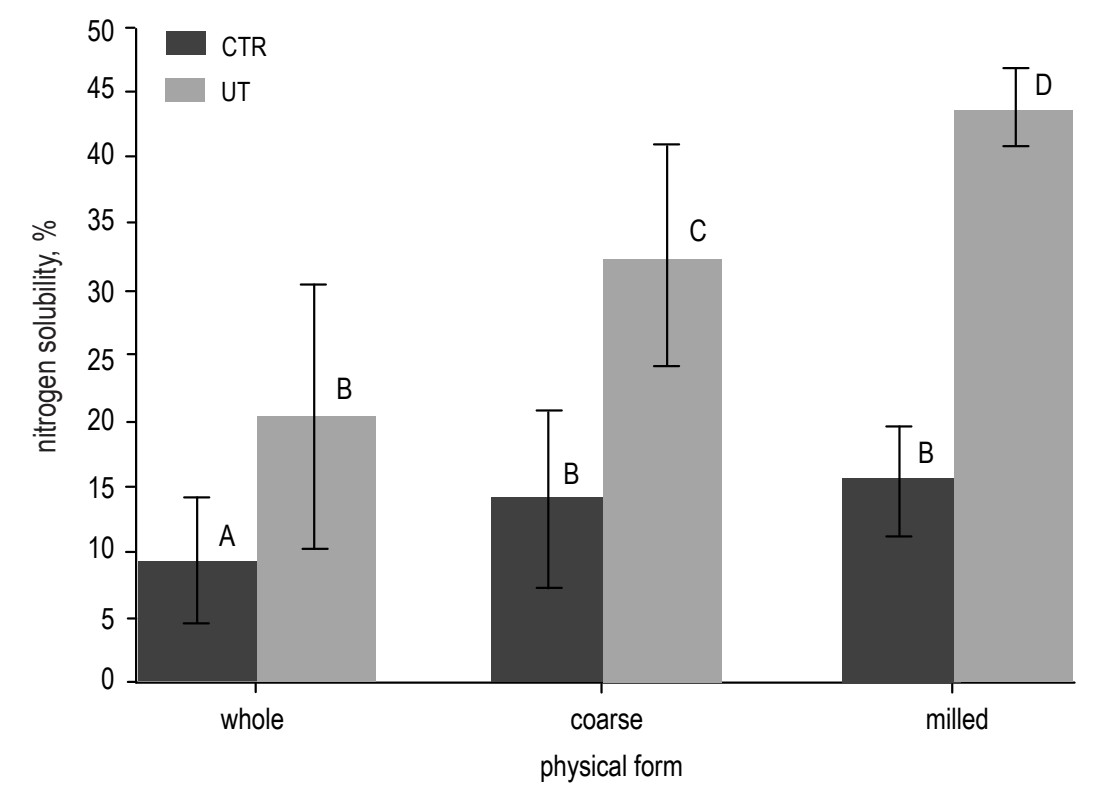

Figure 2. Nitrogen solubility (\%) of cereal grains not-treated or urea-treated (CTR and UT, respectively) and prepared in 3 physical forms: whole grain (whole), coarsely milled (coarse) and milled to $1 \mathrm{~mm}$ (milled) examined in in vitro $\mathrm{N}$ solubility experiment

Interaction 'feed treatment $\times$ physical form' of statistical model used in $\mathrm{N}$ solubility experiment was statistically significant and different letters $(A, B, C, D)$ over the bars indicate statistically different means $(P<0.01$, root mean square error and degrees of freedom: 7.26 and 59 , respectively; vertical lines over the bars indicate the standard deviations) 
tween levels of treatments. In fact, the $\mathrm{pH}$ between cereals was not statistically different at 0 and $8 \mathrm{~h}$ and different at 2 and $4 \mathrm{~h}$ (Figure 1D), while for the feed treatments values were not different at $0 \mathrm{~h}$ and for the others incubation times the CTR samples had the lowest $\mathrm{pH}$ (Figure 1C).

The statistical model in Experiment 2 considered several factors (cereal type, feed treatment, physical form, incubation time) and significant effects were obtained only for the interaction between feed treatment and physical form $(P<0.01$; Figure 2$)$ and for sampling time $(P<0.01)$. In all physical forms the UT samples solubilised more $\mathrm{N}$ than CTR samples (43.7 vs $15.3 \%, 32.4$ vs $14.0 \%$ and 20.3 vs $9.2 \%$ for milled, coarse and whole forms, respectively). Moreover, the UT samples solubilised more $\mathrm{N}$ in the milled form than in the whole form, with the coarse form in the middle; for CTR samples the whole form solubilised the least N (Figure 2). Solubility measured after $1 \mathrm{~h}$ $(18.9 \%)$ increased $(P<0.05)$ to a value of $22.1 \%$ at $2 \mathrm{~h}$ and then further increased $(P<0.01)$ to values between 23.6 and $24.1 \%$ at longer times.

\section{Discussion}

A visual effect of treatment was the browning of the pericarp both in barley and maize, which must be attributed to pigment substances obtained by non-enzymatic reactions of sugars with amines groups (Srivastava and Mowat, 1980).

The first nutritional effect of urea treatment of the cereals was the increase in $\mathrm{CP}$ (3.2 and 3.3 percentage points in barley and maize, respectively) which was in the middle of the range $(0.8-7.2 \%)$ reported in the review of Humer and Zebeli (2017). Calculated recovery of the urea-N added with the treatment was around $74-77 \%$, the remaining probably being lost by volatilization.

The $\mathrm{pH}$ measured after solubilizing in distilled water increased more than 2 points, changing from sub-acid (6.3-6.6) to alkaline conditions (8.2-8.7). The measurement conducted on whole kernels gave comparable results in both kinds of cereals, but the milling resulted in a reduction of $\mathrm{pH}$ in barley and a small increase in maize, which is probably due to differences in mineral and organic matter composition of the cereals.

In the in vitro rumen fermentation experiment (Experiment 1), the ammonia content in fermentation fluid was monitored according with the technique of Cooke et al. (2009), who obtained a progressive accumulation of ammonia using substrates very rich in
$\mathrm{N}$ (e.g., soyabean meal, urea based products). In our experiment, the concentration of ammonia in fermentation fluids was low given the limited $\mathrm{N}$ content of our substrates and was stable within the beginning of incubation (till $6 \mathrm{~h}$, with a weak peak at $4 \mathrm{~h}$ ). During the first hours of incubation there was probably an equilibrium between the ammonia release and its capture for the microbial protein synthesis. In the last part of fermentation, the concentration declined due to a shortage of nitrogenous compounds with respect to the requirements of biosynthesis. As reported by other authors (Srivastava and Mowat, 1980; Mowat et al., 1981), it has been hypothesised that ammonia captured within a cellular matrix might be released slower than free ammonia added to the diet per se as urea. Our hypothesis was proved by the fermentation trial, where the ammonia concentration in UT fermentation fluids was lower than that measured in UA samples.

Results, however, should be considered with some caution, because in samples low in $\mathrm{N}$ content and high in fermentable energy (such as cereals added with limited amounts of urea) it is possible that the different kinetics of ammonia release are masked by the microbial capture for growth. On the contrary, such a limitation could be of low importance in samples characterised by high $\mathrm{N}$ concentrations (e.g., extracted protein meals or urea based products) where the ammonia is in great excess with respect to microbial uptake.

Recently, the ammonia release in the rumen from substrates added with very high amounts of urea (around 10\%) was indirectly measured by the in vitro gas production (Spanghero et al., 2018), but such procedure must still be verified in cereals with much lower urea additions, such as the samples of present paper. Then, in the experiment 2 a possible effect of the physical form of the grains on the rate of ammonia release was evaluated by a water solubility test.

It is well known that ammonia is highly water soluble, while grain proteins are mainly water-insoluble (National Research Council, 1985). In the conducted solubility test the difference between CTR and UT cereals was a gross measure of solubility of $\mathrm{N}$ added as urea. In whole kernels there was a limited difference in $\mathrm{N}$ solubility and this indicates that during the urea treatment ammonia-N penetrated and embedded inside the wet grain kernel structure where it was retained. On the contrary, in milled cereals, the treated samples showed a higher $\mathrm{N}$ solubility than controls because the matrix rupture facilitated the soluble process. The intermediate values found for coarse milled cereals confirm that the 
thinner is the physical form of the treated grain, the lesser is the capacity to retain $\mathrm{NH}_{3}-\mathrm{N}$ inside the grain structure. Moreover, the solubility showed a limited increase during the incubation test (maximum of 5-6 percentage points during the $8 \mathrm{~h}$ of incubation). This fact indicates that water ammonia solubilisation is very rapid and confirms that the process is mainly dependent by the surface of cereal in contact with water. The impact of physical form on solubility could be the reason why the limited slow release effect of UT in Experiment 1 (where all samples were finely milled) was detected.

\section{Conclusions}

The $\mathrm{N}$ added to wet barley and maize kernels by the urea treatment is released in the in vitro rumen fermentation liquid more slowly than that simply added as urea before incubation. Moreover, based on solubility data, the treated whole or cracked kernels have a slower $\mathrm{N}$ release than milled ones. So, the urea treatment of grains adds $\mathrm{N}$ which rate of rumen releasing is dependent on the physical form of cereals fed to animals (e.g., whole, cracked or milled). In vivo experiments, fine-tuned to evaluate rumen $\mathrm{N}$ metabolism, are necessary to confirm present in vitro data.

\section{Acknowledgements}

The authors would like to thank Dr Emilio Cerchiari for technical collaboration. Thanks are due to Erasmus Mundus Action 2 Programme on behalf of the European Commission Erasmus Mundus Iamonet Project.

This work was partly financed by the Methodo Chemicals (Srl, Italy).

\section{References}

AOAC International, 2000. Official Methods of Analysis of AOAC International. 17 ${ }^{\text {th }}$ Edition. Gaithersburg, MD (USA)

Căpriță R., Căpriţă A., Crețescu I., 2010. Protein solubility as quality index for processed soybean. Sci. Pap. Anim. Sci. Biotechnol. 43, 375-378

Cooke R.F., DiLorenzo N., DiCostanzo A., Yelich J.V., Arthington J.D., 2009. Effects of Fermenten ${ }^{\circledR}$ supplementation to beef cattle. Anim. Feed Sci. Technol. 150, 163-174, https://doi. org/10.1016/j.anifeedsci.2008.08.011

Humer E., Zebeli Q., 2017. Grains in ruminant feeding and potentials to enhance their nutritive and health value by chemical processing. Anim. Feed Sci. Technol. 226, 133-151, https://doi. org/10.1016/j.anifeedsci.2017.02.005

Krom M.D., 1980. Spectrophotometric determination of ammonia: a study of a modified Berthelot reaction using salicylate and dichloroisocyanurate. Analyst 1249, 305-316, https://doi. org/10.1039/an9800500305

Martillotti F., Puppo P., 1985. Liquid chromatographic determination of organic acids in silages and rumen fluids. Ann. Ist. Super. Zootec. 18, 1-10

Mowat D.N., McCaughey P., Macleod G.K., 1981. Ammonia or urea treatment of whole high moisture shelled corn. Can. J. Anim. Sci. 61, 703-711, https://doi.org/10.4141/cjas81-085

National Research Council (NRC), 1985. Ruminant Nitrogen Usage. The National Academies Press. Washington, DC (USA), https://doi.org/10.17226/615

Ørskov E.R., Greenhalgh J.F.D., 1977. Alkali treatment as a method of processing whole grain for cattle. J. Agric. Sci. 89, 253-255, https://doi.org/10.1017/S0021859600027465

Ørskov E.R., Stewart C.S., Greenhalgh J.F.D., 1979. The effect of sodium hydroxide and urea on some storage properties of moist grain. J. Agric. Sci. 92, 185-188, https://doi.org/10.1017/ S0021859600060639

Spanghero M., Nikulina A., Mason F., 2018. Use of an in vitro gas production procedure to evaluate rumen slow-release urea products. Anim Feed Sci Technol 237, 19-26, https://doi. org/10.1016/j.anifeedsci.2017.12.017

Srivastava V.K., Mowat D.N., 1980. Preservation and processing of whole high moisture shelled corn with ammonia. Can. J. Anim. Sci. 60, 683-688, https://doi.org/10.4141/cjas80-079 